\title{
Appendix 1 \\ Pamphlets of John Hughlings Jackson, Rockefeller Medical Library, Institute of Neurology, University College London
}

The archives of the Rockefeller Medical Library hold a collection of pamphlets written by John Hughlings Jackson, the only such collection known to exist. Most of these pamphlets reprint articles published in contemporaneous medical periodicals, though one pamphlet was not published elsewhere. There is internal evidence that Hughlings Jackson circulated these pamphlets privately. Some contain marginal comments and corrections in Hughlings Jackson's hand, and in other hands as well.

The Rockefeller Medical Library collection contains five boxes of loose items, which are labelled boxes A-E. Each item is assigned a serial number in the order in which it appears in the collection. The identification number consists of the box letter followed by the serial number.

A3. Suggestions for studying diseases of the nervous system on Professor Owen's vertebral theory

50-page pamphlet. London, H K Lewis, 1863. Preface dated 5 January 1863, at 5 Queen Square. No marginalia. Included in Taylor's and Greenblatt's bibliographies.

A11. On a case of muscular atrophy, with disease of the spinal cord and medulla oblongata

8-page pamphlet. London, J E Adlard, 1867. Authors: J Lockhart Clarke, J Hughlings Jackson. Reprinted from Trans Medico-Chirurgical Soc, series 2, 1867, 32: 489-499. No marginalia.

A15. Cases of disease of the nervous system in patients the subject of inherited syphilis 22-page pamphlet. London, John Churchill and Sons, 1868. Reprinted with alterations from Transactions of the St Andrews Medical Graduates Association, 1867, 1868, 1: 146-160. Two copies, one with inscription "Written 23 years ago. JHJ" in red ink, and other marginal comments in Hughlings Jackson's hand.

A16. Notes on the physiology and pathology of the nervous system 8-page pamphlet. London, B Pardon and Sons, undated. Reprinted from Med Times $G a z, 1868$, ii: 526-528. No marginalia.

A18. Observations on the physiology and pathology of hemi-chorea 12-page pamphlet Edinburgh, Oliver and Boyd, 1868. Reprinted from Edinburgh Med J, 1868, 14, 294-303. Bottom of pages 11-12 cut off. No marginalia. 


\section{Appendix 1}

A19. Observations on defects of sight in brain disease, and ophthalmoscopic examination during sleep

15-page pamphlet. London, Harrison and Sons, 1863. Reprinted from Royal London Ophthalmic Hospital Reports, 1863, 4: 10-19 and 35-37.

A25. A study of convulsions

45-page pamphlet. London, Odell \& Ives, 1870. Reprinted from Transactions of the St Andrews Medical Graduates Association, 1869, 1870, 3: 162-204. Two copies. Copy no. 1 has marginal notes in unknown hand. Copy no. 2 is signed PW (illegible).

A29. On the anatomical, physiological, and pathological investigations of epilepsies 36-page pamphlet. London, Spottiswood and Co., undated. Reprinted from West Riding Lunatic Asylum Medical Reports, 1873, 3: 315-349. Two copies. Copy no. 1 carries printed cover "From the author", with written inscription. Copy no. 2 contains editing marks and notes in pencil and pen.

A30. Clinical and physiological researches on the nervous system. No. 1. On the localisation of movements in the brain

25-page pamphlet plus xlvii page preface, London, J and A Churchill, 1875. Reprinted from a series from Lancet, 1873. Marginal editing notes, comments and corrections.

A33. Observations on the localisation of movements in the cerebral hemispheres, as revealed by cases of convulsion, chorea and "aphasia"

23-page pamphlet. London, Spottiswood \& Co., undated. Reprinted from West Riding Lunatic Asylum Medical Reports, 1873, 3: 175-195. Title-page inscribed in Hughlings Jackson's hand.

A34. A physician's notes on ophthalmology

37-page pamphlet. London, Harrison and Sons, undated. Title-page contains the note: "Chiefly reprinted, with alterations, from the Royal London Ophthalmic Hospital Reports, vol. VII, part 4, 1873, and vol. VIII, part 1, 1874". No marginalia. Mentioned in Taylor's bibliography.

A43. A physician's notes on ophthalmology

37-page pamphlet. London, Harrison and Sons, undated. Title-page carries note: "Reprinted from the Periscope of the Royal London Ophthalmic Hospital Reports Vol VIII, part 2, 1875." No marginalia.

A44. Nervous symptoms in cases of congenital syphilis

Pamphlet. Lewes, Geo. P. Bacon, undated. Carries note: "Reprinted from Journal of Mental Science, January, 1875." No marginalia. 
A46. The syphilitic affections of the nervous system 19-page pamphlet. Lewes, Geo. P. Bacon, undated. Title-page carries note: "Reprinted from Journal of Mental Science, Jul, 1875." No marginalia.

A48. On ocular movements, with vertigo, produced by pressure on a diseased ear 5-page pamphlet. London, Adlard, undated. Reprinted from Trans Ophthalmol Soc $U K, 1883,3: 261-265$. Two copies, copy no. 1 with editing marks.

A49. A case of double optic neuritis without cerebral tumour 13-page pamphlet. London, Harrison and Sons, undated. Reprinted from Royal London Ophthalmic Hospital Reports, 1876, 8: 445-455. Issue dated May 1876. Three copies. Copy no. 1 stamped "E. Arnold Carmichael" and inscribed "J. Hughlings Jackson" in an unknown hand. No marginalia.

A50. Case of large cerebral tumour without optic neuritis and with left hemiplegia and imperception

Pamphlet. London, Harrison and Sons, undated. Reprinted from Royal London Ophthalmic Hospital Reports, 1876, 8: 434-444. Issue dated May 1876. Two copies. Copy no. 1 inscribed "From the Royal London Ophthalmic Hospital Reports May 1876 (Vol 8 Part 3)", with marginal comments in Hughlings Jackson's hand. Copy no. 2 stamped "E. Arnold Carmichael”.

A52. On nervous symptoms with ear disease

10-page pamphlet. London, publisher not given, dated 1877. Reprinted from $\mathrm{Br}$ Med $J$, 1877, i: 349-351. Three copies. Marginal corrections in Hughlings Jackson's hand.

A55. Remarks on the routine use of the ophthalmoscope in cerebral disease 23-page pamphlet. London, Steam Printing Works, 1879. Reprinted from Med Press Circular, 1879, 27: 439-441, 459-461, 479-480. No marginalia. Mentioned in Taylor's bibliography.

A57. On eye symptoms in locomotor ataxy 16-page pamphlet. London, J E Adlard, undated. Reprinted from Trans Ophthalmol Soc UK, 1881, 1: 139-154. Two copies. No marginalia.

A59. Discussion on the relation between optic neuritis and intracranial disease 35-page pamphlet. London, J E Adlard, undated. Reprinted from Trans Ophthalmol Soc UK, 1881, 1: 60-115. Two copies. No marginalia.

A64. The Croonian lectures on evolution and dissolution of the nervous system. Delivered at the Royal College of Physicians, March, 1884 32-page pamphlet. London, British Medical Association, undated. Reprinted from Br Med J, 1884, i: 591-593, 660-663, 703-707. Two copies. Marginal editing comments. 


\section{Appendix 1}

A65. Remarks on evolution and dissolution of the nervous system 24-page pamphlet. Lewes, H Wolff, undated. Reprinted from J Mental Sci, 1887, 33: 25-48. Three copies. Copies nos. 1 and 2 contain editing comments. Copy no. 3 is stamped "E. Arnold Carmichael".

A67. On a case of fits resembling those artificially produced in guinea-pigs 8-page pamphlet. London, Harrison and Sons, undated. Reprinted from Proc Med Soc London, 1886 [published 1887], 10: 78-85. Two copies. No marginalia.

A68. Case of left crural monoplegia with subcortical disease: fracture of left femur, which was cancerous

3-page pamphlet. London, Adlard and Son, undated. Reprinted from Trans Clinical Soc London, 1887, 20: 134-136. Four copies. No marginalia.

A69. An address on the psychology of joking, delivered at the opening of the Medical Society of London, October, 1887

4-page pamphlet. London, British Medical Association, undated. Reprinted from Br Med J, 1887, ii: 870-871. Two copies. Copy no. 1 contains marginal comments in Hughlings Jackson's hand. Copy no. 2 contains a citation in Hughlings Jackson's hand and editing marks in another hand. Copy no. 2 appends a typescript of additional material added to the Selected Writings.

A70. Remarks on evolution and dissolution of the nervous system 40-page pamphlet. London, John Bale and Sons, 1888. Three copies. Copy no. 1 contains reference and marginal comments in Hughlings Jackson's hand. Copy no. 2 contains editing notes. Mentioned in Taylor's bibliography.

A71. On post-epileptic states: a contribution to the comparative study of insanities. First instalment

17-page pamphlet. Lewes, H Wolff, undated. Reprinted from J Mental Sci, 1888, 34: 349-365. No marginalia.

A72. On post-epileptic states: a contribution to the comparative study of insanities. Second instalment

10-page pamphlet. Lewes, H Wolff, undated. Reprinted from J Mental Sci, 1889, 34: 490-500. No marginalia. Stamped "E. Arnold Carmichael”.

A73. On a particular variety of epilepsy ("intellectual aura"), one case with symptoms of organic brain disease

28-page pamphlet. London, Macmillan and Co., 1888. Reprinted from Brain, 1888, 11: 179-207. No marginalia.

A74. Remarks on the diagnosis and treatment of diseases of the brain Pamphlet. London, British Medical Association, undated. Rprinted from $\mathrm{Br} M e d \mathrm{~J}$, 1888, ii: 59-63, 111-117. Three copies. Copy no. 1 inscribed "With best regards. 


\section{Appendix 1}

JHJ", in Hughlings Jackson's hand. Also note on the title-page: "corrected Oct 30th, 1890". Marginal corrections in Hughlings Jackson's hand. Copy no. 2 contains a reference and corrections in Hughlings Jackson's hand and editing marks in another hand. Copy no. 3 has no marginalia.

A79. The Lumleian Lectures on convulsive seizures, delivered before the Royal College of Physicians of London

47-page pamphlet. London, British Medical Association, undated. Reprinted from Br Med J, 1890, i: 703-707, 765-771, 821-827. No marginalia.

A84. The factors of insanities

25-page pamphlet. London, Danks \& Son, 1894. Reprinted from Med Press Circular, 1894, 108: 615-619. Two copies. No marginalia.

A85. A clinical study of a case of cyst of the cerebellum: Weakness of spinal muscles: Death from failure of respiration

6-page pamphlet. London, British Medical Association, 1894. Authors: J Hughlings Jackson and J S Risien Russell. Reprinted from Br Med J, 1894, i: 393-395. No marginalia.

A87. On imperative ideas. Being a discussion of Dr. Hack Tuke's paper (Brain, 1894). 1 - Dr. Hughlings-Jackson

5-page pamphlet. London, Macmillan and Co., 1895. Reprinted from Brain, 1895, 18: 318-322. Editorial comments in unknown hand.

A90. Case of epilepsy with tasting movements and "dreamy state" - very small patch of softening in the left uncinate gyrus

19-page pamphlet. London, Macmillan and Co., 1898. Authors: J Hughlings Jackson and Walter S Colman. Reprinted from Brain, 1898, 21: 580-590. Two copies. No marginalia.

A91. Remarks on loss of movements of the intercostal muscles in some cases of surgical anaesthesia by chloroform and ether 12-page pamphlet. London, Macmillan and Co., 1899. Reprinted from Brain, 1899, 22: 550-562. Authors: J Hughlings Jackson and James S Collier. No marginalia.

A92. On certain relations of the cerebrum and cerebellum (on rigidity of hemiplegia and on paralysis agitans)

9-page pamphlet. London, Macmillan and Co., 1899. Reprinted from Brain, 1899, 22: 621-630. Two copies. Copy no. 1 contains citation and editing marks in unknown hand. Copy no. 2 no marginalia.

A94. Observations on a case of convulsions (trunk fit or lowest level fit?)

10-page pamphlet. London, Macmillan and Co., 1902. Authors: J Hughlings 


\section{Appendix 1}

Jackson and H Douglas Singer. Reprinted from Brain, 1902, 25: 122-132. Two copies. No marginalia.

A95. Further observations on a case of convulsions (trunk fit or lowest level fit?) 6-page pamphlet. London, Macmillan and Co., 1902. Reprinted from Brain, 1902, 25: 286-292. Authors: J Hughlings Jackson and Stanley Barnes. No marginalia.

A97. Case of tumour of the middle lobe of the cerebellum-cerebellar paralysis with rigidity (cerebellar attitude)_occasional tetanus-like seizures

20-page pamphlet. London, Macmillan and Co., 1906. Reprinted from Brain, 1906, 29: 425-440. Two copies. Copy no. 1 inscribed "to be returned to Dr. James Taylor" and stamped "E. Arnold Carmichael". Copy no. 2 has no marginalia. 